\title{
LAS GARANTÍAS CONSTITUCIONALES DE LOS DERECHOS FUNDAMENTALES
}

\author{
Luigi Ferrajoli \\ Universidad de Camerino (Italia)
}

RESUMEN. Una necesaria redefinición de la democracia, sobre la base de la redefinición de la soberanía popular, permite concluir que las garantías de los derechos fundamentales son garantías de la democracia. Ésta, por tanto, comprende cuatro dimensiones: las primeras dos "formales", relacionadas con los derechos-poder de autonomía política y civil; las otras dos "sustanciales", relacionadas con los derechos de libertad y sociales. Las garantías constitucionales se vinculan con la rigidez de la Constitución y consisten en las obligaciones y las prohibiciones correspondientes a las expectativas positivas o negativas normativamente establecidas. Existen pues, de una parte, "garantías positivas" y "garantías negativas". De otra parte, cabe distinguir entre "garantías primarias" (la suma de las anteriores) y "garantías secundarias" (de justiciabilidad, las cuales intervienen en caso de violaciones de la expectativa normativa y de sus garantías primarias).

Palabras clave: Derechos fundamentales, garantías, democracia.

ABSTRACT. If we take the redefinition of the sovereign will of the people as a starting point, a necessary redefinition of democracy leads us to the conclusion that what guarantees fundamental rights also guarantees democracy. This redefinition is, then, made up of four dimensions: the first two are "formal", related to the rights-power of political and civil autonomy; whilst the other two are "substantial", related to social rights and the right to freedom. Constitutional guarantees are linked to the inflexibility of the Constitution and consist in the obligations and prohibitions which correspond to the positive and negative expectations established by norms. Thus, on the one hand, there are "positive guarantees" and "negative guarantees" and, on the other hand, a distinction can be drawn between "primary guarantees" (the sum of those above) and "secondary guarantees" (those of justiciability, which come into effect when normative expectation and its primary guarantees are violated).

Keywords: Fundamental Rights, guarantees, democracy. 


\section{LAS CONCEPCIONES PURAMENTE FORMALES DE LA DEMOCRACIA}

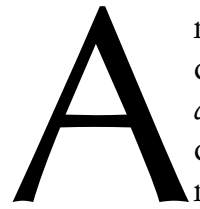

ntes de afrontar el problema de las garantías constitucionales de los derechos fundamentales, me parece oportuna una reflexión sobre la noción de democracia. Según la concepción ampliamente dominante, la democracia consiste en un método de formación de las decisiones públicas: precisamente, en el conjunto de reglas que atribuyen al pueblo o, mejor, a la mayoría de sus miembros, el poder, directo o mediatizado por representantes, de asumir tales decisiones. Ésta no es sólo la acepción etimológica, sino también la concepción de "democracia" casi unánimemente compartida por la mayor parte de las teorías de la democracia: desde KeSEL hasta BobBio, desde SCHUMPETER hasta DAHL, desde POPPER hasta WALDRON ${ }^{1}$. Es también la concepción prevaleciente en la actual filosofía jurídica, como al parecer aflora en las múltiples críticas dirigidas a mí en el marco de dos recientes discusiones en torno a mis tesis: aquella sobre los derechos fundamentales, desarrollada en las páginas de la revista Teoria politica entre 1998 y 2000, y aquella -muy reciente- publicada en el volumen Galantismo, al cuidado de Miguel CARBONELL y de Pedro SALAZAR ${ }^{2}$.

En base a esta concepción, la fuente de legitimación democrática de los poderes públicos es únicamente la autonomía, es decir, la libertad positiva consistente en el «gobernarse a sí mismo» y «en el que no dependa de otro sino de uno mismo la reglamentación de la propia conducta» ${ }^{3}$ : en el hecho, en otras palabras, de que las decisiones sean tomadas, directa o indirectamente, por los mismos destinatarios, o más exactamente, por la mayoría de ellos y sean, por eso, expresión de la "voluntad" y de la "soberanía popular". Podríamos llamar formal o procedimental a esta noción de democracia ${ }^{4}$. En efecto, ella identifica a la democracia simplemente sobre la base de

Recuérdense KelSEN, H., 1929: «Essenza e valore della democrazia», trad. it. en Id., 1981: La democrazia, Bologna: Il Mulino; POPPER, K., 1945: La società aperta e i suoi nemici, trad. it., 1973, Roma: Armando; SCHUMPETER, J. A., 1954: Capitalismo, socialismo e democrazia, trad. it., 1955, Milano: Edizioni di Comunità; BobBIo, N., 1984: Il futuro della democrazia. Una difesa delle regole del gioco, Torino: Einaudi; SARTORI, G., 1957: Democrazia e definizioni, Bologna: Il Mulino; DAHL, R., 1989: La democrazia e i suoi critici, trad. it., 1990, Roma: Editori Riuniti; Bovero, M., 2000: Contro il governo dei peggiori. Una grammatica della democrazia, Roma-Bari: Laterza.

2 Véase, en particular, PInTORe, A., 2000: «Diritti insaziabili», en Teoria politica, n. 2, pp. 3-20, o en FerRajoli, L., 2001: Diritti fondamentali. Un dibattito teorico, al cuidado de Vitale, E., Roma: Laterza, pp. 179200. Véanse también los ensayos de Pedro Salazar Ugarte, de Pablo De Lora y de Andrea Greppi y, si bien en términos problemáticos, de Alfonso Ruiz Miguel en CARbonell, M., y SALAZAR, P. (eds.) 2005: Garantismo. Estudios sobre el pensamiento juridico de Luigi Ferrajoli, Madrid: Editorial Trotta.

3 Bobbio, N. (1954): Della libertà dei moderni comparata a quella dei posteri, o en Teoria generale della politica, al cuidado de Bovero, M., 1999, Torino: Einaudi, p. 230, donde la autonomía es definida como el «poder de darse normas a sí mismos y de no obedecer otras normas que las dadas a sí mismos» (BoBBIO, 1999: p. 228). Es la noción rousseauniana de libertad como «l'obéissance à la loi qu'on s'est prescrite» (RousSEAU, J. J., 1762, Du contrat social, Paris: Garnier-Flammarion, liv. I, ch. 8, p. 56), criticada por KANT: «Mejor es definir mi libertad externa (es decir jurídica) como la facultad de no obedecer a otras leyes externas que no sean aquellas a las que yo he podido dar mi consentimiento», (1795 «Per la pace perpetua», sec. II, en Scritti politici e di filosofia della storia e del diritto, Torino: Utet, p. 292, nota); «la libertad legal [es] la facultad de no obedecer a otras leyes que no sean aquellas a las cuales ellos [los ciudadanos] han dado su consentimiento» ([1797] «Principi metafisici della dottrina del diritto», KANT, 1795: 46, p. 500).

${ }^{4}$ Para que no haya malos entendidos, viene bien precisar que "formal" es usado aquí con referencia a la "forma" de los actos normativos, en oposición a su "sustancia" o "contenido" o "significado prescriptivo" y, por tanto, a la dimensión formal de la validez y — consiguientemente— de la democracia, ligada justamente 
las formas y de los procedimientos dirigidos a garantizar que las decisiones resultantes sean expresión, directa o indirecta, de la voluntad popular. La identifica, en otras palabras, en base al qué (el pueblo y sus representantes) y al cómo (la regla de la mayoría) de las decisiones, independientemente de los contenidos, es decir, de qué cosa se decida, aun si tales contenidos son antiliberales, antisociales e incluso antidemocráticos.

Intentaré, en esta oportunidad, refutar esta concepción simplificada de la democracia. Digo desde ya que es indudable que la dimensión formal de la democracia, como poder fundado sobre la voluntad popular, expresa un rasgo absolutamente necesario: una conditio sine qua non, en ausencia de la cual no se puede hablar de "democracia” en modo alguno. Sin embargo, ¿es ésta únicamente una condición necesaria? La definición de un término debe, por otro lado, indicar la condición no sólo necesaria sino también suficiente en presencia de la cual aquél es predicable de un argumento dado. ¿Es suficiente una connotación puramente formal de la democracia para identificar todas las condiciones en presencia de las cuales un sistema político es clasificable como "democrático" y, más específicamente, como una "democracia constitucional"? Pienso que no lo es. Expondré cuatro razones, correspondientes a otras tantas aporías, que exigen que aquélla esté integrada por límites y vínculos sustantivos o de contenido, como son típicamente los derechos fundamentales.

\section{CUATRO APORÍAS EN LA CONCEPCIÓN PURAMENTE PROCEDIMENTAL DE LA DEMOCRACIA}

La primera razón consiste en la falta de alcance empírico y, consecuentemente, de capacidad explicativa de una definición de democracia que, al identificar únicamente los rasgos formales, no está en condiciones de dar cuenta de las actuales democracias constitucionales, las que resultarían, en esa medida, no-democracias. Semejante definición - limitándose a exigir que los poderes públicos sean ejercitados por el pueblo en la forma que fuere, y configurando así la democracia como poder popular absoluto- ignora o abjura del paradigma del Estado de Derecho, que no admite la existencia de poderes no sometidos a la ley ${ }^{5}$, y —más aún- del Estado constitucional de Derecho, conforme al cual son modeladas las actuales democracias consti-

al respeto de las formas de producción de las normas: en un sentido, por tanto, diverso a aquel según el cual el mismo término es usado por mí como predicado meta-teórico de los conceptos teóricos, es decir, para designar las connotaciones estructurales, independientes de los contenidos normativos denotados por los ordenamientos concretos.

5 Un sistema "democrático" donde la soberanía popular no estuviese sujeta a la ley correspondería plenamente a la noción de estado absoluto definida por HoBBES: «el soberano de un estado, ya sea una asamblea o un hombre, no está sujeto a las leyes civiles. En efecto, al tener el poder de hacer y de abrogar las leyes, si quiere puede liberarse de la sujeción abrogando la ley que le estorba y haciendo una nueva» (2001, Leviatano [1651], trad. it., Milano: Bompiani, parte II, cap. XXVI, 6, p. 433); y más adelante: «Una cuarta opinión incompatible con la naturaleza del Estado es ésta: que quien tiene el poder soberano está sujeto a las leyes civiles... Un soberano no está sujeto a las leyes que él mismo —o sea, el Estado- hace, pues estar sujeto a las leyes es estar sujeto al Estado, es decir, a su representante soberano, que es precisamente él. La suya no es una sujeción, sino una libertad respecto de las leyes. Tal equivocación, al poner las leyes por sobre el soberano, pone también sobre él un juez y un poder que puede castigarlo, lo que supone construir un nuevo soberano y, de esta forma, por el mismo motivo, un tercero que castigue al segundo y así sucesivamente hasta el infinito, con la consecuente confusión y disolución del Estado» (HOBBES, 2001: 9: p. 529). 
tucionales y dentro del cual no es en absoluto verdad que el poder popular sea ilimitado. En efecto, la novedad introducida por el constitucionalismo en la estructura de la democracia es que - en base a él- también el supremo poder legislativo es jurídicamente disciplinado y limitado, en consideración no sólo a las formas, predispuestas en garantía de la afirmación de la voluntad de la mayoría, sino también de la sustancia de su ejercicio, vinculado al respeto de aquellas específicas normas constitucionales que son el principio de igualdad y los derechos fundamentales. ¿Deberemos concluir, con arreglo a la definición formal de democracia únicamente como "poder del pueblo", que estos sistemas no son democráticos? ¿Que los derechos fundamentales sancionados en constituciones rígidas, siendo un límite heterónomo a la dimensión política de la democracia, son por tanto un límite a la democracia tout court, al punto que podrían devenir, siendo tendencialmente "insaciables", una negación de aquélla ${ }^{6}$ ? ¿O debemos afirmar, por el contrario, que precisamente en ausencia de tales límites, si bien podemos hablar de "democracia" en sentido puramente político o formal, no podemos ciertamente hablar de ella por lo que respecta a su forma compleja y hoy generalizada en todos los países avanzados: la "democracia constitucional"?

La segunda razón consiste en la escasa consistencia teórica de un concepto de democracia solamente formal que busque ser consecuente consigo mismo. Algún límite sustancial, en efecto, es necesario para la supervivencia de cualquier democracia. En ausencia de tales límites, relativos al contenido de las decisiones legítimas, una democracia no puede - o, cuando menos, puede no- supervivir: es siempre posible, en línea de principio, que con métodos democráticos se supriman, por mayoría, los mismos métodos democráticos: no solamente los derechos de libertad y los derechos sociales, sino también los mismos derechos políticos, el pluralismo político, la división de los poderes, la representación, en una palabra, el entero sistema de reglas en que consiste la democracia política. No hablo, obviamente, de una hipótesis académica: aludo a las terribles experiencias totalitarias del fascismo y del nazismo del siglo pasado, los cuales conquistaron el poder en forma democrática y después lo entregaron "democráticamente" a un caudillo que suprimió la democracia. Normalmente (pienso en las tesis de Norberto BobBio y Michelangelo Bovero), esta objeción viene envuelta en la tesis de que los límites a la democracia asegurados por algunos derechos fundamentales son "condiciones", o "precondiciones", o "presupuestos" o "límites" de la democracia $^{7}$. Sin embargo, una condición, cuando es considerada necesaria, equivale a un

\footnotetext{
Es la tesis de PINTORE, 2000: pp. 179-200.

Véase, por ejemplo, BOBBIO, 1984: Il futuro della democrazia, Torino: Einaudi, p. 6, que «también para una definición mínima de democracia, como es la que acojo», se requiere, conjuntamente con el sufragio universal y el principio de mayoría, una «tercera condición»: la posibilidad de elegir entre «alternativas reales» para cuya realización «se necesita que a los llamados a decidir se les garanticen los denominados derechos de libertad, de opinión, de expresión de la propia opinión, de reunión, de asociación, etc. Las normas constitucionales que atribuyen estos derechos no son propiamente reglas del juego: son reglas preliminares que permiten el desarrollo del juego». En el mismo sentido, véase BOVERO, 2000: cap. II, 6: pp. 38-41; BOVERO, 2002: «Democracia y derechos fundamentales», Isonomía, 16, abril, pp. 21-38, donde viene criticado el uso - para mí apropiado- de la palabra "democracia" para designar las connotaciones sustanciales impresas por los derechos fundamentales en la "democracia constitucional". Una crítica diversa —al uso del predicado "sustancial" asociado a "democracia" para designar esas mismas connotaciones- que fuera dirigida a mí en BOVERO, M., 1993: «La filosofia politica di Ferrajoli», en Gianformaggio, L. (al cuidado de), Le ragioni del garantismo, Torino: Giappichelli, pp. 399-406; cfr. mi respuesta, GianformagGIO, 1993: pp. 505-508.
} 
requisito esencial y, por tanto, está necesariamente incluida, como condición sine qua non, en la definición del término a definir.

La tercera razón consiste en el nexo indisoluble, ignorado por la concepción puramente formal de la democracia, entre la soberanía popular, la democracia y las dos clases de derechos fundamentales que he llamado "sustanciales" 8 . Sobre todo los derechos de libertad. En efecto, la voluntad popular se expresa auténticamente sólo si puede expresarse libremente. Y puede expresarse libremente sólo a través del ejercicio, más allá del derecho a voto, de las libertades fundamentales por parte de todos y cada uno: de la libertad de pensamiento, de prensa, de información, de reunión, de asociación. Por esto, no hay soberanía popular sin derechos de libertad individual. Pues no solamente que la democracia política y la misma soberanía popular son amenazadas - también para las generaciones futuras, como diré más adelante- por la omnipotencia de la mayoría, sino que la una y la otra se realizan y se alimentan únicamente a través del ejercicio constante de los derechos fundamentales de libertad. Por otro lado, los derechos de libertad, a su vez, son efectivos en la medida en que son sostenidos por la garantía de los derechos sociales a prestaciones positivas: del derecho a la subsistencia y a la salud y, más obviamente aún, del derecho a la educación y a la información. Sin la satisfacción de estos derechos, no solamente los derechos políticos sino también los derechos de libertad están destinados a quedarse en el papel: por cuanto no hay participación en la vida pública sin garantía del mínimo vital, es decir, del derecho a la supervivencia, ni hay formación de voluntad consciente sin instrucción ni información.

La cuarta razón de la insuficiencia de una noción de democracia puramente formal viene dada por una aporía de carácter filosófico-político. Esta concepción formal o procedimental se erige, como se ha dicho, sobre la base de la connotación de la democracia como "auto-nomía" o "auto-gobierno" o "auto-determinación" popular, o sea, como libertad positiva del pueblo de no estar sujeto a otra decisión, y por tanto a otros límites o vínculos que los deliberados por sí mismo. Sin embargo, el pueblo es un sujeto colectivo, que no puede sino deliberar en mayoría y —además, en la democracia representativa - a base de la elección de sus representantes. La ecuación entre auto-nomía y método de decisión fundado sobre los principios de mayoría y representación envuelve, por tanto, una concepción comunitaria, organicista y holista de la representación y de la democracia basada sobre la idea —marcadamente ideológica, populista y, en último análisis, fascista- de que el pueblo es un "cuerpo político" ${ }^{\text {, }}$ una suerte de organismo, un macro-sujeto dotado de una propia voluntad homogénea y que los principios de la representación y de la mayoría, antes que simples convenciones — con mayor idoneidad que las demás— para determinar los sujetos mayo-

\footnotetext{
${ }^{8}$ En FerRajoli, 2001: I, $\$ 4$, p. 19; III, $\$ 2$, p. 284.

9 Recuérdense los célebres pasajes de RousSEAU: «Instantáneamente, en vez de la persona particular de cada contratante, este acto de asociación produce un cuerpo moral y colectivo, compuesto de tantos miembros como votos tiene la asamblea, el cual recibe de este mismo acto su unidad, su yo común, su vida y su voluntad. Esta persona pública que así se forma, por la unión de todos los demás, tomaba en otro tiempo el nombre de ciudad y toma ahora el de república o de cuerpo político... Respecto a los asociados, toman colectivamente el nombre de pueblo» (1966, liv. I, ch. VI, p. 52); «Mediante el pacto social hemos dado existencia y vida al cuerpo político; se trata ahora de darle el movimiento y la voluntad mediante la legislación» (RousSEAU, 1966: liv. II, ch. VI, p. 73).
} 
ritariamente "representativos", son realmente la forma mediante la cual se expresa la voluntad general y unitaria del pueblo como sujeto unitario y orgánico ${ }^{10}$. Mientras que, si abandonamos esta insidiosa metáfora, debemos reconocer, como escribe Hans KELSEN en polémica con Carl SCHMITT, que una semejante voluntad unitaria no existe y su asunción ideológica sólo sirve para legitimar el poder absoluto de la mayoría, y quizás de su caudillo, y para ocultar la pluralidad de los intereses y de las opiniones y el conflicto de clases que atraviesan el considerado "pueblo" 11.

\section{UNA REDEFINICIÓN DE LA SOBERANÍA POPULAR COMPATIBLE CON EL PARADIGMA DE LA DEMOCRACIA CONSTITUCIONAL}

El reconocimiento de estas aporías y, por tanto, de la insuficiencia de una definición solamente formal del concepto de democracia, impone a mi juicio una reconsideración radical de la relación entre pueblo y democracia, sobre la base de una redefinición de la noción de "soberanía popular" que sea compatible con la de "democracia".

De esto se sigue, sobre todo, que cualquier concepción de la soberanía como potestas legibus soluta está en contradicción no sólo con la idea de democracia constitucional sino con la idea misma de democracia, manifestada históricamente y lógicamente incompatible con la existencia de poderes soberanos o absolutos, incluida la omnipotencia de la mayoría del pueblo o de sus representantes ${ }^{12}$. Precisamente para sanear esta contradicción, por lo demás, el constitucionalismo se ha afirmado, en el siglo pasado, como garantía de la democracia, después de la experiencia de los fascismos que en forma políticamente democrática habían primero conquistado el poder y luego destruido la democracia. De aquí el nexo estructural entre democracia y constitucionalismo. El que un sistema político sea democrático supone que a la mayoría le sea constitucionalmente sustraído el poder de suprimir o de limitar la posibilidad de que la minoría llegue a ser mayoría, mediante límites y vínculos que establezcan aquello que Ernesto GARZÓN VALDÉs ha llamado el "coto vedado", es

\footnotetext{
10 «Pero ¿qué cosa es este pueblo?», se pregunta KeLSEN: «una pluralidad de individuos sin duda. Y parece que la democracia presupone, fundamentalmente, que esa pluralidad de individuos constituya una unidad, tanto más que el pueblo como unidad es —o debería teóricamente ser — no tanto objeto cuanto sujeto del poder. Sin embargo, apenas se toman en consideración los hechos sensibles, aquella unidad que aparece con el nombre de pueblo se presenta problemática. Fraccionado por contrastes nacionales, religiosos y económicos, el pueblo aparece, a los ojos del sociólogo, más bien como una multiplicidad de grupos distintos que como una masa coherente de uno y de un mismo estado de aglomeración» (1981: cap. II, pp. 50-51).

${ }^{11}$ Kelsen, H., 1931: «Chi deve essere il custode della costituzione?», trad. it. en KelsEN, 1981: La giustizia costituzionale, Milano: Giuffrè, pp. 275-276.

${ }_{12}$ Scrive CONSTANT, B., 1818-1819: «Principes de politique», en Cours de politique constitutionnelle, trad. it., 1970: Principi di politica, Roma: Editori Riuniti, cap. I, p. 54: «Cuando se afirma que la soberanía del pueblo es ilimitada», añade CONSTANT, «se crea y se establece en la sociedad humana un grado de poder demasiado grande, que constituye un mal cualquiera sean las manos en las que se lo confíe. Ya se confíe a uno, a muchos o a todos siempre se obtendrá un mal. Se atacará a los depositarios de ese poder y, en su momento, según las circunstancias, se acusará a la monarquía, a la aristocracia, a la democracia, a los gobiernos mixtos, al sistema representativo. Se cometerá un error; no hay que acusar a los depositarios de la fuerza, sino al grado de ésta. Hay que exasperarse contra el arma y no contra la mano que la sostiene. Hay armas demasiado pesadas para los hombres»; CONSTANT, 1970: p. 60: «La soberanía el pueblo no es ilimitada; está circunscrita dentro de los confines trazados por la justicia y los derechos de los individuos. La voluntad de todo un pueblo no puede volver justo aquello que es injusto».
} 
decir, una esfera de aquello que es "no decidible" por parte de ninguna mayoría. Sin embargo, está claro que estos límites y vínculos, impuestos a los poderes de la mayoría mediante la estipulación constitucional de derechos fundamentales y de las correspondientes garantías, no son normas formales, sino sustanciales, que tienen que ver con los contenidos de las decisiones, cuya validez sustancial - y no simplemente formal- condicionan, y que por tanto contradicen la tesis según la cual la democracia consistiría únicamente en un método, es decir, en las reglas procedimentales que aseguran la representatividad popular mediante el sufragio universal y el principio de mayoría.

Hay, sin embargo, dos significados que pueden ser asociados a la noción de "soberanía popular", relacionados el uno con la noción general de democracia, el otro con aquella más específica de democracia constitucional.

El primer significado de "soberanía popular" compatible con la democracia es el literal, referido al pueblo entero, el cual está expresado por ejemplo en el art. 1 de la Constitución italiana («La soberanía pertenece al pueblo») y en el art. 1 párr. 2 de la Constitución española («La soberanía popular reside en el pueblo español») ${ }^{13}$. En este significado literal, el principio de la soberanía popular no es otra cosa que un principio de legitimación, en negativo, de la democracia política. Quiere decir, simplemente, que la "soberanía pertenece al pueblo" y solamente al pueblo; que reside en el pueblo y solamente en el pueblo. Esta misma idea estuvo en ROSSEAU, cuando afirmó que «la soberanía no puede ser representada, por la misma razón que no puede ser alienada, ella consiste esencialmente en la voluntad general, y la voluntad no se representa: o es ella misma, o bien es otra cosa; no hay vía intermedia» ${ }^{14}$. Esto quiere decir que el principio de la soberanía popular equivale a una garantía negativa, es decir, una prohibición para todos de usurparla: significa que ella, perteneciendo al pueblo entero, no pertenece a nadie más y ninguna persona o grupo de personas en particular - monarca o parlamento, presidente electo por el pueblo o asamblea representativapuede apropiarse de ella ${ }^{15}$. En este sentido, el principio de la soberanía popular o nacional, con aparente paradoja, antes que presentarse reñido con el principio del Estado de Derecho, según el cual no existen poderes soberanos o legubis soluti en cabeza de ningún hombre o grupo de hombres distinto al pueblo entero, representa su primera garantía.

13 «La souveraineté réside dans le peuple», declaró el art. 25 de la Declaración de los derechos preámbulo de la Constitución de 1793; y el art. 7 añade: «Le peuple souverain est l'universalité des citoyens français». Afirmaciones análogas se encuentran en casi todas las principales constituciones de hoy: en el art. 1 de la Constitución japonesa de 1946; en el art. 20 párr. 2 de la Constitución alemana de 1949; en el art. 3 de la Constitución francesa de 1958; en el art. 1 de la Constitución griega de 1975; en los arts. 1 y 3 de la Constitución china de 1975; en los arts. 1, 2 y 3 apartado $1 .^{\circ}$ de la Constitución portuguesa de 1976.

${ }^{14}$ Rousseau, J. J., 1966: liv. III, ch. XV, p. 134.

${ }_{15}$ Constant, B., 1818: «La sovranità del popolo e i suoi limiti», en Principes de politique, con sucesivos añadidos y variaciones, 1962: Antologia degli scritti di Benjamin Constant, al cuidado de ZANFARINO A., Bologna: Il Mulino, p. 59, nota 1: «El axioma de la soberanía del pueblo se considera un principio de libertad: es, más bien, un principio de garantía. Está destinado a impedir a un individuo apoderarse de la autoridad que, antes bien, pertenece a toda la sociedad; pero no decide nada sobre la naturaleza y los límites de esta autoridad». Recuérdese también el art. 3 de la Constitución francesa de 1958, que luego de establecer en el primer apartado que «la soberanía nacional pertenece al pueblo» afirma en el segundo apartado que «ninguna fracción del pueblo ni ningún individuo puede atribuirse su ejercicio». 
El segundo significado que puede ser asociado a la expresión "soberanía popular", de acuerdo con el paradigma de la democracia constitucional, es aquel referido a su nexo con los derechos fundamentales constitucionalmente establecidos. Ya se ha dicho que todos los derechos fundamentales dan forma y contenido a la "soberanía popular" y a la "voluntad popular", la cual no puede manifestarse auténticamente si no puede expresarse libremente, y no puede manifestarse auténticamente sin estar presidida por las garantías, no sólo de los derechos políticos, sino también de los derechos de libertad y de los derechos sociales. Por tanto, la fórmula «la soberanía pertenece al pueblo» quiere decir, en este segundo sentido, que aquélla pertenece al conjunto de los ciudadanos, es decir, a todas las personas de las cuales el pueblo se compone: pertenece, en suma, a todos y a cada de los ciudadanos. Mas esto significa, en concreto, que aquélla no es otra cosa que la suma de aquellos poderes y contrapoderes de todos - los derechos políticos, los derechos civiles, los derechos de libertad y los derechos sociales-, cuales son los derechos fundamentales constitucionalmente establecidos: los que, por tanto, no son únicamente los límites de la democracia política, sino que son también la sustancia democrática, en cuanto se refieren al pueblo en un sentido mucho más concreto y penetrante que la mera representación política, es decir, a todos y cada uno de sus miembros de carne y hueso. Tales derechos equivalen, por tanto, en cabeza de cada una de las personas, a otros tantos fragmentos de la soberanía del pueblo entero. Por ello, cada una de sus violaciones no son únicamente una lesión de las personas que son titulares, sino que es una violación de la misma soberanía popular. Recordemos el famoso art. 34 de la Declaración antepuesta a la Constitución del 24 de junio de 1793: «Hay opresión contra el cuerpo social cuando uno solo de sus miembros es oprimido. Hay opresión contra cada miembro cuando el cuerpo social es oprimido» ${ }^{16}$.

\section{LA RIGIDEZ DE LA CONSTITUCIÓN Y LAS GARANTÍAS CONSTITUCIONALES}

Llego, así, al tema de mi ponencia. Si todo esto es verdad, las garantías constitucionales de los derechos fundamentales son también garantía de la democracia. Varias veces he desagregado la noción de democracia constitucional vinculándola con las cuatro clases de derechos en las cuales he dividido la categoría de derechos fundamentales. La democracia política, asegurada por la garantía de los derechos políticos; la democracia civil, asegurada por la garantía de los derechos civiles; la democracia liberal, asegurada por la garantía de los derechos de libertad; la democracia social, asegurada por la garantía de los derechos sociales.

De aquí resulta una noción cuatridimensional de la democracia como modelo normativo que articula cuatro dimensiones: las primeras dos "formales", por cuanto son relativas a la forma democrática (al "qué” y al "cómo") de la decisión, la cual está ase-

16 Es el principio expresado en el famoso art. 34 de la Declaración preámbulo de la Constitución del 24.6.1793: «Existe opresión contra el cuerpo social cuando uno solo de sus miembros es oprimido. Hay opresión contra cada miembro cuando el cuerpo social es oprimido». Recuérdese también el nexo entre "garantía social" de los derechos consistente en la "acción de todos" en su defensa y "soberanía nacional" instituido en el art. 23 de la Déclarations des droits preámbulo de la Constitución francesa del 24.6.1793. 
gurada por los derechos-poder de autonomía política y civil; las otras dos "sustanciales”, pues son relativas a la sustancia de la decisión (al "qué cosa” está permitido o no está permitido decidir), la cual está asegurada por los derechos sustanciales de libertad y sociales ${ }^{17}$. En este sentido, el garantismo, el cual es descomponible en sus cuatro dimensiones — política, civil, liberal y social, según la clase de derechos garantizados-, es la otra cara del constitucionalismo y forma el presupuesto de la democracia.

¿En qué cosa consisten las "garantías constitucionales”? Con esta expresión se alude normalmente a la "rigidez" de la Constitución, es decir, a la no modificabilidad de los principios, de los derechos y de los institutos en ella previstos si no es mediante procedimientos de revisión agravados, y al control jurisdiccional de la constitucionalidad respecto de las leyes ordinarias reñidas con aquélla. Se trata en realidad de una noción compleja, que aquí descompondré en varias nociones distintas: por un lado, la rigidez, que es un rasgo de la norma constitucional; por otro lado, el conjunto complejo y articulado de sus garantías, que requieren, a su vez, ser distinguidas y analizadas.

La rigidez constitucional no es, propiamente, una garantía, sino un rasgo estructural de la constitución ligado a su ubicación en el vértice de la jerarquía de las normas; de modo que las constituciones son rígidas por definición, en el sentido de que una Constitución no rígida no es, en realidad, una Constitución sino una ley ordinaria ${ }^{18}$. Se identifica, en suma, con el grado de las normas constitucionales supraordenado al de todas las otras fuentes del ordenamiento, es decir, con la normatividad de las primeras respecto de las segundas. Referida a las normas constitucionales que establecen aquellas expectativas universales que son los derechos fundamentales, ella confiere a éstos, por tanto, una doble normatividad: como expectativas negativas de su no derogación o violación y, junto a ello, como expectativas positivas de su ejecución ${ }^{19}$.

La cuestión de la rigidez constitucional o, mejor, del grado de rigidez que está justificado asociar a una Constitución y, más precisamente, a los diversos tipos de normas constitucionales, remite por otra parte al problema del que he hablado hasta ahora, el de la relación entre democracia política y derechos fundamentales. Respecto de ella se contraponen — desde antiguo — dos tesis, la una garantista, la otra — por así decir"democrática", sostenidas ambas con los valores asociados al poder y al acto constituyente: aquélla, sostenida por Benjamín CONSTANT, de la inmodificabilidad de al menos algunos principios de aquellos establecidos como fundamentales ${ }^{20}$, pues no existiendo ningún poder constituido superior al poder constituyente, éste se agota con su ejercicio; y aquélla, que se remonta a SIEYÈS, de la permanente modificabilidad de

17 Remito a Ferrajoli, 2001: III, 6, pp. 318-320 y 2, pp. 282-288.

18 Sobre los caracteres estructurales, o si se quiere "naturales" de la rigidez de la Constitución en cuanto tal, cfr. PACE, A., 1993: «La "naturale" rigidità delle costituzioni scritte», in Giurisprudenza costituzionale, pp. 4085 y ss., e PACE, A., 1996: La causa della rigidità costituzionale. Una rilettura di Bryce, dello statuto albertino e di qualche altra costituzione, Padova: Cedam.

19 Sobre la noción de "derecho subjetivo" como expectativa positiva (a prestaciones) o negativa (a no lesiones), remito a FERRAJOLI, 2001: I, p. 5.

${ }^{20}$ Es la tesis, sostenida por CONSTANT, B., 1814: «Réflexions sur les costitutions», en ConSTANT, 1982: Cours de politique constitutionnelle, Genève-Paris: Slatkine, pp. 265 y ss., según la cual no son modificables por vía legislativa las normas sobre la forma de gobierno y las relativas a los derechos constitucionalmente establecidos. 
cualquier principio constitucional por obra de un poder constituyente constantemente en práctica, como expresión permanente de la democracia política ${ }^{21}$.

El argumento principal presentado en apoyo de esta segunda tesis es el de que una excesiva rigidez de la Constitución serviría para limitar los poderes constituidos de las generaciones futuras y, más en general, los principios de la democracia política: para "atarles las manos", como se ha dicho eficazmente. Es el argumento de la primacía de la voluntad popular, expresado en el art. 28 de la Constitución francesa de 1973, según el cual «Un pueblo tiene siempre el derecho de revisar, de reformar y de cambiar su Constitución» y «una generación no puede sujetar a sus leyes a las generaciones futuras».

Ahora bien, este argumento puede ser, en mi opinión, derribado. Ya he hablado de la valía sustancialmente democrática de los derechos fundamentales y de sus nexos con la soberanía popular en cuanto poderes y contrapoderes conferidos, sobre todo en el momento constituyente caracterizado por el velo de la ignorancia frente a contingentes intereses de parte, de todos y de cada uno, y por consiguiente del pueblo entero. El principio del constante derecho de todas las generaciones a decidir sobre su futuro puede ser, sobre esta base y con aparente paradoja, presentado en apoyo de la tesis exactamente opuesta a aquella de la existencia de un permanente y radical poder constituyente como expresión de la soberanía popular: en apoyo, precisamente, de la tesis de que verdaderamente la rigidez de la Constitución es, al mismo tiempo, expresión y garantía de la soberanía popular de las generaciones futuras y de los mismos poderes de las futuras mayorías. Precisamente con fundamento en esto, en efecto, debe ser impedida la revisión cuando menos de los principios constitucionales supremos, establecidos en salvaguardia permanente de la soberanía popular y de los poderes de la mayoría: como, por ejemplo, el método democrático, los derechos políticos y el sufragio universal, los mismos derechos de libertad y quizás los mismos derechos sociales, que forman el presupuesto elemental de los derechos políticos. La rigidez, en otras palabras, ata las manos de las generaciones - en su momento- presentes, para impedir que sean amputadas, por ellas, las manos de las generaciones futuras. De aquí resulta que un pueblo puede incluso decidir, democrática y contingentemente, ignorar o destruir la propia Constitución y encomendarse definitivamente a un gobierno autoritario. Pero no puede hacerlo en forma constitucional, invocando a favor de sí mismo el respeto de los derechos de las generaciones futuras o la omnipotencia de la mayoría, sin con esto suprimir, con el método democrático, los mismos derechos y el mismo poder inherentes a la mayoría y a las generaciones del futuro.

${ }^{21}$ La tesis se remonta a SIEYĖs: «Una nación no puede alienar ni prohibirse el derecho de querer; y, cualquiera sea su voluntad no puede perder el derecho a cambiarla cuando su interés lo exija», 1992 (1788, Che cosa è il terzo stato?, trad. it., Roma: Editori Riuniti, cap. V, p. 59: El principio está además enunciado en el art. 1 del título VII de la Constitución francesa de 1971: «L'Assemblée nationale constituante déclare que la Nation a le droit imprescriptible de changer sa Constitution» (y a tal fin prevé, en los arts. 2-8, un procedimiento especial de revisión), y luego en el art. 28 de la Constitución francesa del 24 de junio de 1793: «Un peuple a toujours le droit de révoir, de réformer et de changer sa constitution. Une génération ne peut assujettir à ses lois les générations futures». La misma tesis fue expresada por PAINE, T., 1791-1792: Rights of Man, trad. it., 1978: I diritti dell'uomo e altri scritti politici, al cuidado de MAGRI, T., Roma: Editori Riuniti, p. 122: «cada generación está y debe estar en grado de afrontar todas las decisiones requeridas por las circunstancias de su tiempo». 
Aclarado el sentido de la rigidez de la Constitución, es fácil también aclarar la naturaleza de sus garantías constitucionales. Asumo aquí "garantía" en el significado varias veces convenido por mí $^{22}$ : para designar las obligaciones y las prohibiciones correspondientes a las expectativas positivas o negativas normativamente establecidas. Hablaré, por tanto, de "garantías negativas" para designar las prohibiciones correspondientes a las expectativas negativas, y de "garantías positivas" para designar las obligaciones correspondientes a las expectativas positivas. Hablaré además de "garantías primarias" para designar la suma de las garantías positivas y de aquellas negativas, y de "garantías secundarias" para designar las garantías de justiciabilidad, las cuales intervienen en caso de violaciones de la expectativa normativa y de sus garantías primarias.

\section{LAS GARANTÍAS CONSTITUCIONALES NEGATIVAS, POSITIVAS, PRIMARIAS Y SECUNDARIAS}

La tesis que intento sostener es que la rigidez de las normas constitucionales impone al legislador ordinario dos clases de garantías constitucionales, conectadas entre sí como las caras de una misma medalla y correspondientes a la doble naturaleza, de aspecto negativo y de aspecto positivo, que — como se ha dicho- revisten, en particular, los derechos fundamentales con ellas establecidos: por un lado, las garantías negativas, consistentes en la prohibición de derogar; por el otro, las garantías positivas, consistentes en la obligación de realizar lo dispuesto por ellas.

Las garantías constitucionales negativas, es decir, las consistentes en prohibiciones, son las de la inderogabilidad de la Constitución por parte del legislador ordinario, al cual impiden la producción de normas reñidas con ella. Aquéllas son dos: a) las normas sobre la revisión constitucional, que impiden cualquier revisión o que prevén, para la modificación de las normas constitucionales, procedimientos más agravados que aquellos previstos por las leyes ordinarias; $b$ ) las normas sobre el control jurisdiccional de constitucionalidad de los actos preceptivos reñidos con las normas constitucionales, por comisión o por omisión, por razones de forma o sustancia. En efecto, las normas de esta clase no se identifican con la rigidez, que como he dicho es un rasgo estructural de la Constitución, generada por su ubicación en el vértice de la jerarquía de las fuentes, sino con sus garantías negativas. Precisamente, las normas sobre la revisión son la garantía negativa primaria, consistente en la prohibición de la producción de normas de ley que violen o deroguen normas constitucionales, esté aquélla incondicionada o condicionada a la adopción de un procedimiento legislativo agravado. Las normas sobre el control jurisdiccional de constitucionalidad son, en cambio, la garantía negativa secundaria, consistente en la anulación o en la inaplicación de las normas de ley reñidas con las normas constitucionales y, por tanto, en violación de su garantía negativa primaria.

Las garantías constitucionales negativas primarias representadas por las normas sobre la revisión pueden ser más o menos vinculantes, de acuerdo con el grado de rigidez de esa garantía: una rigidez absoluta, donde la revisión es radicalmente excluida

22 Sobre la distinción entre "garantías primarias" y "garantías secundarias", remito a FERRAJOLI, 2001: I, \$2, p. 11, y Ferrajoli, L., 1999: «Garanzie», in Parole-chiave, n. 19, pp. 15-32. 
por ellas; una rigidez relativa, donde ellas predisponen formas más o menos agravadas de revisión. En el primer caso, hay límites absolutos, formulados en algunas constituciones - como la Constitución francesa del 3 de septiembre de 1791, el art. 79, apartado $3 .^{\circ}$, de la Constitución alemana de 1949 y el art. 288 de la Constitución portuguesa de 1976- en términos relativamente precisos y taxativos ${ }^{23}$. En el segundo caso, hay límites relativos, lo que permite hablar de un grado más o menos elevado de rigidez relativa, de acuerdo con el grado de agravamiento del procedimiento de revisión previsto, respecto del procedimiento legislativo ordinario. Pero, además de los límites explícitos a la revisión dictados por la misma Constitución, existen también límites implícitos, hoy ampliamente reconocidos tanto por la doctrina como por la jurisprudencia, como aquellos relativos al método democrático y a los derechos fundamentales. Por ejemplo, el art. 2 de la Constitución italiana declara "inviolables" los «derechos del hombre, ya como individuo ya en las formaciones sociales donde se desenvuelve su personalidad»; y una sentencia constitucional, la n. 1.146 de 1988, ha establecido la sustracción al poder de la revisión de los «principios supremos del ordenamiento», no expresamente enumerados por ella, aunque ciertamente identificados, en el plano teórico, con aquellos implícitos en la noción misma de constitución democrática y de rigidez constitucional.

Esta diferenciación de las garantías constitucionales negativas primarias, por otra parte, siempre se ha realizado (o no realizado) en ausencia de cualquier diseño teórico. Por el contrario, una ciencia de la Constitución debe, según mi parecer, teorizar y proponer diversos grados de rigidez de las diversas normas constitucionales, basados en su diversa relevancia democrática: por ejemplo, la rigidez absoluta de las normas que establecen el principio de igualdad, la dignidad de la persona y los derechos fundamentales, para los cuales estaría previsto el posible reforzamiento mas no la posible reducción, así como los principios de la representación política y de la separación de los poderes; formas más o menos agravadas de rigidez relativa para las normas sobre la organización y el funcionamiento de los poderes públicos; formas leves de rigidez relativa, en fin, para las normas menos importantes.

Por otro lado, también las garantías constitucionales negativas secundarias, consistentes en el control jurisdiccional de constitucionalidad, pueden ser más o menos incisivas. Históricamente, se han desarrollado dos tipos de control judicial sobre la legitimidad de las leyes: a) el control difuso, implantado en los Estados Unidos y en otros ordenamientos americanos, consistente en la inaplicación en el caso decidido - pero no en la anulación - de la norma inconstitucional, que queda - por ello- en vigor incluso después del reconocimiento de su ilegitimidad, salvo el valor de hecho vinculante del precedente, tanto más autorizado si procede de la Corte Suprema; $b$ ) el control concentrado, implantado en Italia y en muchos otros países europeos en la segunda posguerra sobre la base del modelo kelseniano adoptado por la Constitución austríaca

${ }^{23}$ El título I de la Constitución francesa del 3 de septiembre de 1791 establecía: «Le Pouvoir législatif ne pourra faire aucunes lois qui portent atteinte et mettent obstacle à l'exercice des droits nauturels et civils consignés dans le présent titre et garantis par la Constitution». El art. 79, III parágrafo de la Ley fundamental alemana de 1949 establece: «Está prohibida toda modificación de la presente Ley Fundamental que afecte la organización de la Federación en Länder, o la máxima de la participación de los Länder en la legislación, o los principios enunciados en los arts. 1 y 20». El art. 288 de la Constitución portuguesa enumera catorce materias puestas a salvo del poder de revisión. 
de 1920, consistente en la anulación de las normas de ley inconstitucionales, reservada a una Corte constitucional -investida para resolver controversias como lo hace un juez en el curso de un juicio- cuando se trate de una cuestión relevante y no manifiestamente infundada.

De los dos modelos, el más eficaz es sin duda el segundo: «una Constitución que carece de la garantía de la anulación de los actos inconstitucionales —escribe KELSEN-, no es, en sentido técnico, completamente obligatoria» ${ }^{24}$. Pero también el segundo modelo, el del control concentrado de constitucionalidad experimentado en Europa, presenta múltiples límites: en el aspecto objetivo, dado que no revisa, por ejemplo en el Derecho italiano, cualquier acto normativo reñido con la Constitución sino solamente las fuentes primarias, es decir, las leyes ordinarias y todos los actos a ellas equiparadas; y en el aspecto subjetivo, dado que los legitimados para elevar la cuestión de inconstitucionalidad no son normalmente, como de nuevo en Italia, los sujetos lesionados por las normas sospechosas de ilegitimidad sino, incidentalmente, los jueces, si la consideran fundada y relevante en los casos sometidos a su juzgamiento. En cuanto al primer aspecto, el control bien podría ser extendido a actos no legislativos: como, por ejemplo, la participación en la guerra, cuyo solemne repudio, enunciado en el art. 11 de la Constitución italiana, salvo el caso de "defensa" previsto en el art. 52, no está asistido por ninguna garantía constitucional. En cambio, mucho más difícil y problemático, como diré más adelante, es la extensión del control de constitucionalidad a las lagunas, es decir, a las violaciones de la Constitución no por comisión (como son las antinomias generadas por normas inválidas), sino por omisiones: un control previsto por la Constitución portuguesa y por la brasileña que, sin embargo, encuentra un límite insuperable en la naturaleza del juicio de nulidad y caducidad del comprobado acto inválido, que es característica de la jurisdicción de legitimidad ${ }^{25}$. En cuanto al segundo aspecto, se precisaría extender a otros sujetos, además de los jueces a quo, la legitimación para elevar la cuestión de inconstitucionalidad. Pienso en el instituto del juicio de amparo, presente en muchos ordenamientos latino-americanos y accionable por cualquier individuo contra toda disposición lesiva de un derecho constitucionalmente establecido. Pero pienso, sobre todo, en la propuesta avanzada de Hans KELSEN, de la institución, junto a la Corte constitucional, de un procurador general, denominado por él «defensor de la Constitución», con la tarea de objetar la ilegitimidad de cualquier acto del Parlamento por él considerado inconstitucional ${ }^{26}$.

\footnotetext{
${ }^{24}$ Kelsen, H., «La garanzia giurisdizionale della costituzione», en KELSEN, 1981: 22, p. 199: «Aunque en general no se tenga consciencia de ello», prosigue KELSEN, «una constitución en la cual los actos constitucionales, y en particular las leyes, permanecen válidos — ya que su constitucionalidad no es anulada- equivale, prácticamente, desde el punto de vista jurídico, a un deseo privado de fuerza obligatoria. Toda ley, reglamento o - incluso- acto jurídico general efectuado por los particulares tiene una fuerza jurídica superior a la de una constitución semejante, a la cual, sin embargo, dichos actos están subordinados y de la cual extraen su validez».

${ }^{25} \mathrm{El}$ art. 283 de la Constitución portuguesa del 2.4.1976 y el art. 103 de la Constitución brasileña de 1988, dedicados a la «inconstitucionalidad por omisión» se limitan a prever el señalamiento de la laguna por parte del Tribunal Constitucional al órgano legislativo y, en el caso de la Constitución brasileña, la intimación a colmarla «dentro de treinta días».

${ }_{26}$ «Una institución del todo nueva, pero que amerita la más seria consideración es la de un defensor de la constitución ante el tribunal constitucional que, a semejaza del ministerio público en el procedimiento penal, debería iniciar de oficio el procedimiento de control de constitucionalidad respecto de los actos que consi-
} 


\section{LA GARANTÍA CONSTITUCIONAL POSITIVA. LA LAGUNA DE GARANTÍA}

Aún más importantes que las garantías constitucionales negativas son las garantías constitucionales positivas, extrañamente descuidadas, o - peor-ignoradas por la doctrina, a pesar de que son indispensables, en particular, para la efectividad de los derechos fundamentales constitucionalmente establecidos. Aquéllas consisten en la obligación, a la cual está vinculado el legislador en correspondencia con tales derechos, de establecer una legislación de ejecución: en suma, en la obligación de introducir las garantías primarias y secundarias correlativas a los derechos fundamentales estipulados.

Arribo así a la cuestión central del garantismo - la de la relación entre derechos fundamentales y garantías-, sobre la cual se ha desarrollado, en un reciente debate, una — ahora - ya vieja polémica. Me refiero a las críticas repetidamente dirigidas por Ricardo GUASTINI, por Danilo ZOLO y por Pablo DE LORA a mi tesis según la cual, en ausencia de garantías, es decir, de obligaciones de deberes correspondientes a los derechos constitucionalmente establecidos, no habría, como yo sostengo, una laguna, sino la inexistencia de los derechos establecidos. Habría finalmente, a despecho de su estipulación constitucional, la inexistencia no sólo de las garantías, sino también de los derechos en sí mismos ${ }^{27}$.

No propondré de nuevo los términos de la cuestión entera. Me limito a poner de manifiesto que en la base de estas críticas hay la confusión entre derecho y garantía, avalorada por la autoridad de KELSEN. En efecto, según KELSEN, como sabemos, el derecho subjetivo sería sólo el «reflejo de un deber jurídico» ${ }^{28}$, o sea, de aquello que he llamado aquí "garantía primaria”. Mejor: tener un derecho, añade KELSEN, equivale a tener «la posibilidad jurídica de provocar la aplicación de la correspondiente norma jurídica que provee la sanción» ${ }^{29}$; en otras palabras, equivale a activar aquella

derara irregulares. El titular de una función tal debería tener, evidentemente, las más amplias garantías de independencia posibles, tanto frente al gobierno como frente al parlamento» (KELSEN, 1981: 19, p. 196).

${ }^{27}$ Es la tesis sostenida por GUASTINI, R., «Tre problemi di definizione», en FERRAJOLI, 2001: pp. 43-48, y por ZOLO, D., «Libertà, proprietà ed uguaglianza nella teoria dei 'diritti fondamentali», en FERRAJOLI, 2005: pp. 49-55. Véase mi réplica 2005: pp. 156-171. Una tesis análoga es sostenida por DE LoRA, P., «Luigi Ferrajoli y el constitucionalismo fortísimo», en CARBOnEll, M., y SAlazAr, P. (edd.), 2005: 3, pp. 255-259.

${ }^{28}$ Kelsen, H., 1960: La dottrina pura del diritto, trad. it., Torino: Einaudi, 29, a, p. 150: «Si se define como "derecho" la relación entre un individuo (que se encuentra obligado respecto de otro a determinada conducta) con este último individuo, el derecho en cuestión es solamente un reflejo de ese deber»; KELSEN, 1945: Teoria generale del diritto, trad. it., Milano: Edizioni di Comunità, parte I, VI, A, p. 76: «no hay por tanto ningún derecho para alguna persona sin un deber jurídico para alguna otra. El contenido de un derecho subjetivo es, en definitiva, el cumplimiento del deber de otro sujeto»; KeLSEN, 1945: C, a, p. 77: el derecho «no es más que el correlato de un deber».

29 KELSEN, 1959: C, d, 82-83. «En este sentido», prosigue KELSEN, «esta norma constituye "su” ley. Solamente si la aplicación de la norma jurídica, la ejecución de la sanción, depende de la expresión de la voluntad de un individuo orientada hacia tal objetivo, es decir, solamente si la ley está a disposición de un individuo, ésta puede ser considerada "su” ley, su ley subjetiva, y esto significa un "derecho subjetivo" ». Pues bien: «el derecho subjetivo, por tanto, tiene que consistir no en el presunto interés, sino en la protección jurídica... El derecho subjetivo, en suma, no es sino el mismo derecho objetivo» (KELSEN, 1959: C, c, p. 81); «la esencia del derecho subjetivo, cuando es más que el mero reflejo de un deber jurídico, consiste en el hecho de que una norma jurídica atribuye a un individuo el poder jurídico de reclamar, por el incumplimiento de un deber jurídico, mediante una acción judicial» (KELSEN, 1966: 29, d, p. 159). 
que aquí he llamado "garantía secundaria". KELSEN — quizá porque sus referencias son únicamente a los derechos patrimoniales, que en efecto son siempre producto de actos negociales, al igual que sus deberes correspondientes- efectúa claramente, por lo tanto, dos identificaciones: entre los derechos y las correlativas garantías primarias y entre los derechos y las correlativas garantías secundarias.

Esta singular disolución de los derechos en las garantías es el precio pagado por KELSEN por su concepción imperativista del Derecho, basada sobre la centralidad de la sanción. Se trata, sin embargo, de un precio demasiado alto, que contradice la premisa normativista y iuspositivista de su misma teoría. De aquí se deriva, en efecto, que derechos formalmente puestos o producidos por actos normativos válidos pero privados de garantías serían, simplemente, derechos inexistentes; que inexistentes - simples flatus vocis - serían también las normas que los expresan; que enteros catálogos de derechos - gran parte de los derechos sociales y casi todos los derechos humanos establecidos por convenciones internacionales- serían no-derechos, no-normas, solamente por estar privados de garantías, tanto primarias como secundarias.

Es una tesis que indudablemente contradice dos postulados del normativismo, al mismo tiempo metateóricos y teóricos. En primer lugar, contradice el postulado del positivismo jurídico, en cuanto desconoce la positividad de las normas jurídicas, las cuales en un sistema nomodinámico existen si son puestas o producidas, y no se corresponden con un principio teórico arbitrario (la efectiva producción, en correspondencia con los derechos constitucionalmente establecidos, de los correlativos deberes), como si la teoría pudiera desarrollar funciones legislativas. Contradice, en segundo lugar, el postulado del constitucionalismo, en cuanto desconoce el grado supraordenado a toda otra fuente de las normas constitucionales y de los derechos en ellas establecidos, cuya existencia no puede estar subordinada a la producción (obligatoria) de sus leyes de ejecución, dado que una tesis similar equivaldría, como adecuadamente escribe Michelangelo BOVERO, a decretar el poder del legislador para frustrar, o para abrogar o de todos modos para derogar la Constitución y para, así, ocultar su violación ${ }^{30}$.

Al contrario, es la estructura nomodinámica del Derecho positivo la que impone distinguir entre los derechos fundamentales constitucionalmente establecidos y sus garantías legislativas. Puesto que en un sistema nomodinámico, como precisamente KELSEN nos ha enseñado, la existencia de las normas está ligada a un hecho empírico, es decir, al acto de su producción, es perfectamente posible que dado un derecho fundamental expresado por una norma constitucional, no exista — si bien debería existir- la obligación o la prohibición correspondiente a causa de la (indebida) inexistencia de la norma que debería preverlos; así como es perfectamente posible que, dada la facultad de un comportamiento, por ejemplo un derecho de libertad, exista - si bien no debería existir - la prohibición del mismo comportamiento a causa de la (indebida) existencia de la norma que lo prevé. Es perfectamente posible, en suma, que en ordenamientos complejos, en los que se articulan múltiples niveles normativos, se produzcan lagunas y antinomias. Esta posibilidad es un corolario del constitucionalismo rígido, cuyo rasgo característico es, por consiguiente, el espacio virtual que él abre

${ }^{30}$ Bovero, M., «Derechos, deberes, garantías», en Carbonell, M., y Salazar, P., 2005: pp. 237-238. 
para la existencia del derecho ilegítimo, causada por la posible inobservancia, por parte del legislador, de la obligación de ejecutar la norma constitucional.

Es precisamente esta obligación —la obligación de una legislación de ejecución, consistente en la introducción de las garantías primarias y secundarias faltantes- la que integra la garantía constitucional positiva de los derechos fundamentales establecidos. No es, por tanto, verdad que la carencia de garantías legislativas primarias y secundarias equivale a la carencia de cualquier obligación en cabeza del legislador: de modo que, como escribe GUASTINI, debemos o abandonar la definición de "derecho subjetivo" como expectativa a la que corresponde un deber, o bien negar la existencia del derecho a pesar de hallarse constitucionalmente establecido ${ }^{31}$. Como bien ha puesto de relieve Michelangelo BOVERO, existe una obligación ${ }^{32}$, y es precisamente la de introducir las garantías correspondientes al derecho estipulado. Es en esta obligación de una legislación de ejecución que podemos identificar la garantía constitucional positiva primaria de los derechos constitucionales establecidos. Se trata de una garantía débil en un doble aspecto: en primer lugar, por la dificultad de asegurar la efectividad mediante una garantía constitucional positiva secundaria como sería el control jurisdiccional de constitucionalidad sobre las lagunas; en segundo lugar, porque aquélla es, por así decir, una meta-garantía, consistente en la obligación de introducir legislativamente la garantía fuerte constituida por las garantías primarias y secundarias correspondientes al derecho constitucionalmente establecido.

Por lo demás, todos los derechos fundamentales constitucionalmente establecidos requieren legislación de ejecución que disponga las garantías, si éstas no han sido producidas - como sí sucede con los derechos patrimoniales-, en correspondencia con los derechos garantizados. Por ejemplo, si se toma la estipulación constitucional, con el derecho a la vida, o bien con un derecho de libertad como el habeas corpus, o bien con un derecho social como el derecho a la salud. A falta de la prohibición penal del homicidio o de la garantía procesal de la libertad personal o de una legislación social en materia de asistencia sanitaria - es decir, en ausencia de garantías fuertes, tanto primarias como secundarias - tales derechos son destinados a permanecer en el papel. Mas, ciertamente, no diremos que ellos no existen porque no existe, como requiere la definición de derecho subjetivo, el deber o la obligación correspondiente. Existe, en efecto, la obligación constitucional de introducir estas garantías fuertes —es decir, de colmar las lagunas-, aquélla realiza y satisface, como garantía constitucional positiva, la tesis teórica del nexo de implicación entre derecho y garantía.

Pues bien, es propiamente en la laguna o en la inefectividad de las garantías legislativas, es decir, de las leyes de ejecución de los derechos constitucionalmente establecidos - en particular de los derechos sociales, como el derecho a la salud, a la instrucción y a la subsistencia-, donde reside hoy el principal factor de ilegitimidad constitucional de nuestros ordenamientos. La ausencia de garantías es prácticamente total en el Derecho internacional. Con la sola excepción de las instituciones de la Corte penal internacional para los crímenes contra la humanidad, el ordenamiento internacional es casi del todo carente de instituciones de garantía: tanto que se puede identi-

\footnotetext{
31 Guastini y Ferrajoli, 2001: pp. 43-44.

32 Bovero, Carbonell y Salazar, 2005: pp. 238-243.
} 
ficar la globalización, en el plano jurídico, como un vacío casi total de una esfera pública, esto es, de garantías a la altura de los múltiples derechos fundamentales solemnemente proclamados en las numerosas declaraciones y convenciones internacionales sobre derechos humanos.

Sin embargo, también a nivel estatal, las democracias constitucionales son incompletas en múltiples aspectos respecto de los densos catálogos de principios y de derechos establecidos en sus constituciones rígidas. En muchos ordenamientos, primero que todo, carecen de las garantías primarias de muchos derechos sociales. Y carecen, sobre todo, de las técnicas jurídicas idóneas para constreñir a los poderes públicos a introducirlas. Carecen incluso, en muchos casos, de las técnicas garantistas idóneas para impedir o reparar el desmantelamiento, en marcha en muchos países, de muchas de las garantías sociales existentes. También para los derechos de libertad, por otro lado, las clásicas garantías primarias de las prohibiciones de sus lesiones y las secundarias de la condena de sus ofensas y de la anulación de las normas con ellas reñidas son del todo inidóneas para ponerlas a salvo de las viejas y nuevas insidias y agresiones, provenientes no sólo de los poderes políticos sino también de los grandes poderes económicos privados. Incluso los derechos políticos pueden ser frustrados, si el ordenamiento no dispone de eficaces defensas jurídicas, por los métodos electorales establecidos, por la concentración de los medios de información y por las lesiones causadas a la representación por las derive plebiscitarie y por los conflictos de intereses. Todas estas lagunas y todos estos variados aspectos de inefectividad deben, por tanto, ser entendidos como las múltiples causas de ilegitimidad. Podemos, de hecho, identificar el grado de legitimidad del ordenamiento de una democracia constitucional con el grado de efectividad de las garantías de los derechos constitucionalmente establecidos; e identificar la ilegitimidad con sus violaciones o - peor- con su laguna.

(Trad. de Alí Lozada) 